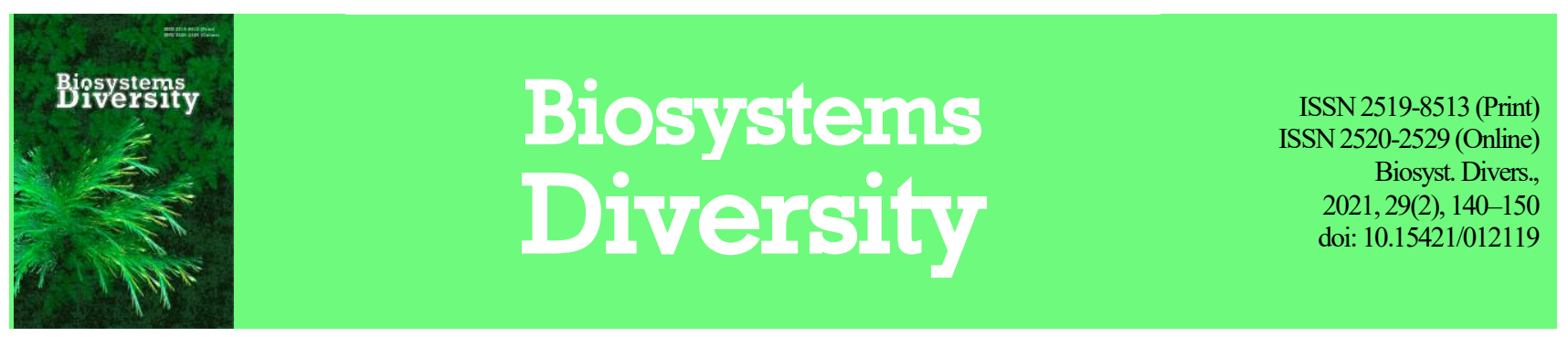

\title{
Modeling the bioclimatic range of Pterostichus melanarius (Coleoptera, Carabidae) in conditions of global climate change
}

\author{
T. A. Avtaeva*, R. A. Sukhodolskaya**, V. V. Brygadyrenko***,**** \\ *K. Ibragimov Complex Institute of the Russian Academy of Sciences, Grozny, Russia \\ **Research Institute for Problems of Ecology and Mineral Wealth Use of Tatarstan Academy of Sciences, Kazan, Russia \\ ***Oles Honchar Dnipro National University, Dnipro, Ukraine \\ ****Dnipro State Agrarian and Economic University, Dnipro, Ukraine
}

Article info

Received 15.05.2021

Received in revised form 14.06 .2021

Accepted 15.06.2021

Complex Institute named after K. I. Ibragimov of the Russian Academy of Sciences,

Staropromyslovskoe highwav, 21a, Grozm

364051, Russia. Tel.: +793-890-709-82.

E-mail:avtaeva1971@mail.ru

Research Institutefor Problems of Ecology and Mineral Wealth Use of Tatarstan Academ of Sciences, Daurskava st., 28, Kazan, 420087 Russia. Tel.: +795-031-526-19.

E-mail: sukhodolskayaraisa@gmail.com

Oles Honchar Dnipro National University, Gagarin av., 72, Dnipro, 49010, Ukraine. Tel. +38-050-93-90-788.E-mail:brigad@ua.fm

Dnipro State Agrarian and Economic

University, Serhii Efremov st., 25, Dnipro,

49600, Ukraine. Tel.: +38-050-93-90-788.

E-mail:brigad@ua.fm

\author{
Avtaeva, T. A., Sukhodolskaya, R. A., \& Brygadyrenko, V. V. (2021). Modeling the bioclimatic range of Pterostichus \\ melanarius (Coleoptera, Carabidae) in conditions of global climate change. Biosystems Diversity, 29(2), 140-150. \\ doi:10.15421/012119
}

At present, climate change significantly affects living organisms on the planet, leading to transformations in their niches, ranges and abundance. The aim of our work was to forecast the range of the representative of the large family Carabidae, famous for its indicative characters, richness and importance in soil communities. We used 19 bioclimatic variables of Bioclim according to our own data and the data of GBIF with the help of the MaxEnt program. We used 550 coordinates of ground beetle Pterostichus melanarius (Illiger, 1798) records. We distinguished the potential range the species studied and drew prognostic maps of the species' distribution related to climate change according to four scenarios. Mean annual temperatures and the mean temperature in the warmest and the coldest quarters of the year were the major factors affecting spatial distribution of P. melanarius. Visualization of potential range according to RCP $2.6, \mathrm{RCP} 4.5$ and RCP 6.0 scenarios predicted range reduction by 2050 but its recovery by 2070 . According to RCP 8.5 scenario, the range of the species studied will be significantly transformed: by 2070 the range will shift towards the north-west in the continental European states but to the northeast - in the coastal states. By 2070 almost all southern territories of Europe will become unsuitable for P. melanarius survival. The most visible changes will be the shift in range to the north in the eastern part of the European plain. The comfort conditions for $P$. melanarius decrease in mountain regions including the Alps, Carpathians, Caucasus and Urals. By 2070, the cenotic optimum significantly decreases on the Balkan Peninsula. Thus, a sharp reduction in Southern European and Mediterranean populations is predicted.

Keywords: climate; GIS; GBIF; predicted area; climatic factors; distribution; ground beetles.

\section{Introduction}

Investigation into the impact of climate factors on organisms is a relevant scientific problem (Thiele, 1977). In studying a species range, determination of the optimal temperatures and humidity for it in different seasons can help predict changes in its range in the context of global change in temperature and humidity (Avtaeva et al., 2019). Pterostichus melanarius (Illiger, 1798) is a vital element in temperate ecosystems. It dominates numerically in carabid communities in cities (Magura et al., 2008; Putchkov et al., 2020) and it is especially well studied in agrocenoses (Armstrong \& McKinlay, 1997; Symondson et al., 1997; Haw6thorne et al., 1998; Sharova et al., 1998; Banks, 1999; Carmona \& Landis, 1999). It dwells near industrial enterprises as well, in polluted zones (Lindqvist \& Block, 2001; Elek et al., 2014), it is common in different types of anthropogenically disturbed forest ecosystems (Brygadyrenko, 2016).

Mechanisms allowing P. melanarius to survive on plots where other carabid species die out due to industrial pollution are not well studied (Thomas et al., 1997; Brygadyrenko, 2015; Komlyk \& Brygadyrenko, 2019). Seemingly, habitat fragmentation leading to extinction of many other species does not negatively affect $P$. melanarius (Thiele, 1977; Thomas et al., 1998; Putchkov et al., 2019). Probably significant individual variation in feeding abilities is responsible for this phenomenon (Korolev \& Brygadyrenko, 2014) and the high morphological variation in this species as well (Brygadyrenko \& Korolev, 2015; Cottrell-Callbeck et al., 2019).

Pterostichus melanarius is a transpalearctic mesophilic species (Kryzhanovskij et al., 1995; Freude et al., 2004; Putchkov, 2011, 2018). Its life cycle is polyvariant with multiseasonal reproduction and hibernation of larvae, adults of the first and second years of life (Sharova \& Denisova, 1997; Matalin, 2006). It is widely distributed in Europe. Its southem distribution extends to northern Spain and its eastern - to the Amur River (Bousquet, 2003). It is introduced in North America (Niemelä \& Spence, 1994; Niemela et al., 1997).

Feeding resources affect its distribution (Kielty et al., 1999). The preferences of $P$. melanarius in the selection of potential food objects have been studied. In a laboratory experiment, $P$. melanarius consumed 75 $100 \%$ of Formicidae individuals provided, Silphidae larvae, small species of Staphylinidae, Coccinellidae, Dermestidae, larvae of Lepidoptera, Hemiptera, Thomisidae, Opiliones, Lumbricidae (Korolev \& Brygadyrenko, 2012a, 2012b). This species readily feeds on other carabid species (Stomis pumicatus Pz., Harpalus amplicollis Men., Panagaeus bipustulatus F., Leistus ferrugineus L., Notiophilus laticollis Chd., species of Bembidion and Amara genera, and other Carabidae species larvae) (Korolev \& Brygadyrenko, 2012a, 2012b). In turn other large predators (ground beetles Carabus gramulatus Linnaeus, 1758, Broscus cephalotes (Linnaeus, 1758) and staphilins Staphylinus caesareus Cederh) prey on P. melanarius (Brygadyrenko \& Korolev, 2006).

As a generalist species, P. melanarius is regarded as a good model species for the purposes of study of morphometric variation in differing environments (Brygadyrenko \& Korolev, 2015). Its high abundance in a wide range of biotopes (including islands and flooded plots on floodplains) and urbanized cenoses allowed vast databases on morphometric variation in this species to be created. The latter are used in studies of body 
size variation in insects along geographical gradients and also in relation to carabids' adaptation to anthropogenic impact (Sukhodolskaya, 2013, 2014).

Climate change affect life-cycles and therefore ranges of all carabid species. In this relation it was interesting to investigate the potential range of the most common species, though the rare ones are not less important. The species studied in our investigation is not threatened with extinction. But it is of certain interest to predict changes in its range in the coming 30 50 years under the influence of global climate shifts. The aim of this study was to reveal tendencies of changes in distribution of $P$. melanarius under different scenarios of global climate change in 2050 and 2070.

\section{Materials and methods}

Material for this study was collected in the field by the authors (150 sites), and the data was obtained from the GBIF open data base as well (400 sites in: GBIF Secretariat (2019). GBIF Backbone Taxonomy. Checklist dataset doi:10.15468/39omei accessed via GBIF.org).

Sampling was performed in different years on the territory of Russia (Tatarstan, Chechen Republic and others) and different provinces of Ukraine. In the Chechen Republic the species is observed in the floodplain forests and in the mixed mountain forests as well. In the former its number is significantly higher. In Ukraine the species dominates in the major types of man-made disturbed landscapes (Brygadyrenko, 2016; Putchkov, 2018; Putchkov et al., 2020). In Tatarstan, P. melanarius is recorded in natural biotopes ( 10 plots) and at sites with anthropogenic transformation (2 plots, Fig. 1). Samples from other provinces were kindly presented to the authors from our colleagues in the frames of Agreements about Scientific Collaboration.

In total 20,187 individuals were sampled by authors themselves. We used $0.5 \mathrm{~L}$ pitfall traps and manual sampling in litter and under stones. The traps were $0.5 \mathrm{~L}$ volume with $4 \%$ formalin or acetic acid. At every site 20 traps were used with $10 \mathrm{~m}$ distance between each of them. Beetles were taken out of traps every ten days. Sampling period has been longed from 1996 till 2019. Sampling years differed in different regions.

For bioclimatic modeling (Avtaeva et al., 2019), WorldClim data of global base of climatic data (www.worldclim.org) were used: 19 bioclimatic variables with spatial resolution of 2,5 minutes.

We used the most informative indexes for the bioclimatic niche estimation formed by 19 bioclimatic parameters: bio 1 - mean annual air temperature; bio 6 - the minimal temperature in the year's coldest month; bio 10 - the mean temperature in the year's warmest quarter; bio 11 - the mean temperature of the year's coldest quarter; bio 14 - precipitation sum in the driest month of the year.

The climatic model CCSM 4 (Community Climate System Model) was used in the models. We took into account 4 climate change scenarios: RCP2.6 (implies temperature increase on the planet to $0.9^{\circ} \mathrm{C}$ on an average); RCP4.5 (increase to $1.9^{\circ} \mathrm{C}$ ); RCP6.0 (increase to $2.4^{\circ} \mathrm{C}$ ); RCP8.5 (increase to $4.1^{\circ} \mathrm{C}$ ). We selected historical period according to the latest recommendations of the WMO (Directive of WMO, 2017).

We used QGIS 3.16.1 (Quantum GIS, 2020) for working with layers. Predicting potential range was made using Maxent 3.4.4 program (Phillips SJ, Dudík M, Schapire RE (2017) MaxEnt software for modeling species niches and distributions (Version 3.4.1), http:/biodiversityinformatics.amnh.org/open_source/maxent.

We used data of authors, publications and the open base on biodiversity GBIF, bioclimatic parameters from the open base WorldClim and the method of maximal entropy to perform multivariate analysis of climate niche and reveal the major factors affecting the present distribution of P. melanarius.

To verify the models we used the square (AUC) under the ROCcurve $(\mathrm{ROC}$ - receiver operating characteristic - errors curve, AUC - area under the curve - the area under the errors curve). Estimation of model accuracy parameters was done on the randomly formed test samples. For model estimation 25 was pointed (random test percentage), i.e. from the whole points of presence array the program would randomly select $25 \%$ for the following testing of the model received. Thus, $75 \%$ of data would be used for model construction as the educational sample, and $25 \%$ as the testing one. The threshold of binarization prediction estimated the model's prognostic abilities: conditions were regarded as suitable for species exis- tence, if the prediction was higher than some threshold value, and vice versa. Usually the threshold by 10 percentiles is used. The latter indicates that $90 \%$ points of presence array, taken into analysis, fall into "potential" range. Remaining not fallen $10 \%$ are regarded as dwelling in atypical conditions and are not taken into account when climatic niche construction.

AUC estimates the model's ability to recognize species presence or absence in localities. In our model the mean was $0.972 \pm 0.005$. It means, that the probability of studied species presence in the noted points was $97.0 \%$, i. e. the model significance was sufficiently high (Fig. 2).

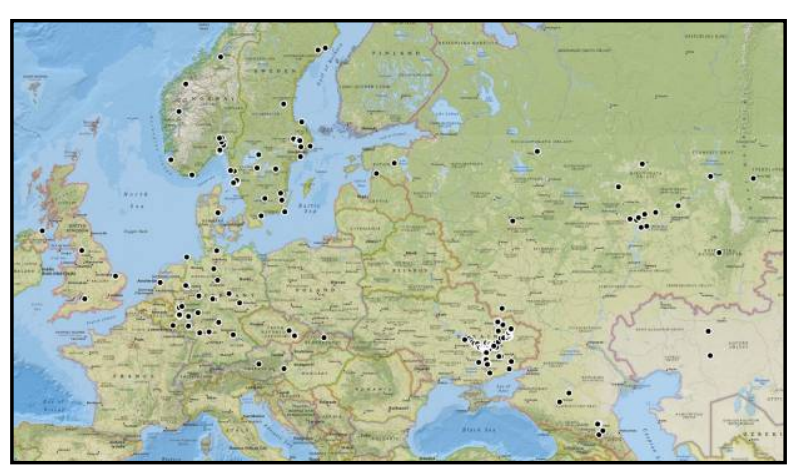

Fig. 1. Points of $P$. melanarius presence
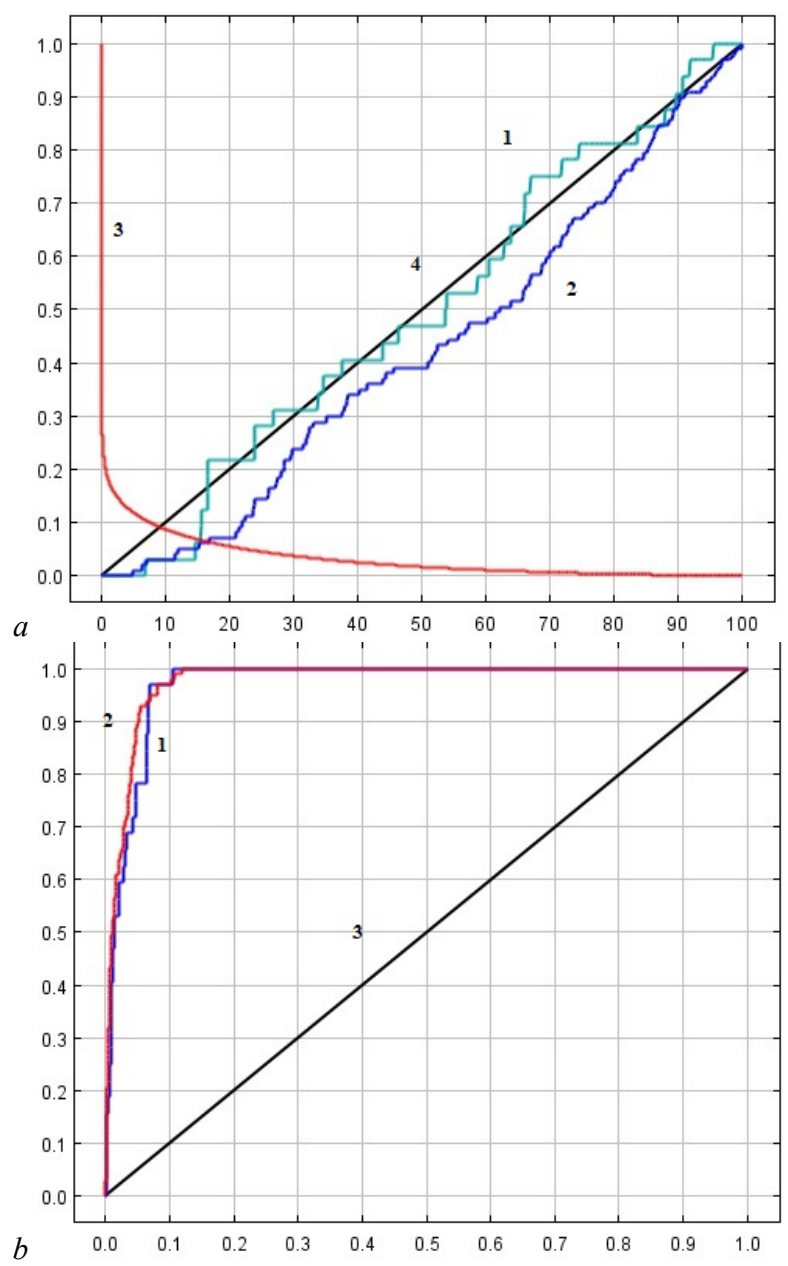

Fig. 2. Analysis of the prognostic distribution model accuracy: $a-$ omission and predicted area for $P$. melanarius $(1-$ test data,

2 - training data, 3 - input data fraction that were predicted, 4 - predicted emission); $b$-operational curve trend AUC ( 1 - test data, 2 - training data, 3 - random prediction)

The modeling problem suggests supplementing the constructed model by the points of absence. In our study the number of randomly selected absence points was 10000, in accordance to Phillips et al. (2017). 
Model adequacy is determined by the traits choice as well. We used for this purpose all bioclimatic parameters from WorldClim base. The latter were filtered in relation to importance for the species spatial distribution. Then to the remaining variables we applied the sequential elimination algorithm with the constant AUC marcks tracking.

We used the parameter "importance when permutating" to estimate each factor's impact. According to it the contribution of each variable is determined due to the random shifts of its values and AUC decrease estimation. In the MaxEnt program the comfort range varies between 0 and 1 . We used jackknife function when estimating variables contribution to the resulting model.

We estimated squares of the temporary bioclimatic areas in the species studied and the predicted area as well. In MaxEnt media we constructed Table 1 . We analyzed records and bioclimate parameters to reveal the four most important environmental factors for the studied species. The third column of the table includes estimation of variables after permutation. Each variable contribution is formed as the result of random change of this variable value in analysis. The latter includes all data taken into the "education" process: points of real species presence and "background" as well. It was important because the contribution estimation was affected by the final model, not by the way of its construction. The advice of the software implementators was very carefully highly correlated with the variables estimation.

\section{Results}

Permutation changed contributions of the precipitation in the driest month of the year (Table 1). Mean annual air temperature, mean temperatures in the warmest and the coldest quarters of the year and minimal temperature of the coldest month became the most significant. Permutation coefficient maximal values were recorded for those data. They showed the relative importance of factors when constructing the model with the correlation with the other variables.

Table 1

Estimation of bioclimatic parameters affecting $P$. melanarius distribution

\begin{tabular}{lcc}
\hline \multicolumn{1}{c}{ Parameters } & $\begin{array}{c}\text { Percent } \\
\text { contribution }\end{array}$ & $\begin{array}{c}\text { Permutation } \\
\text { importance }^{* *}\end{array}$ \\
\hline Sum of precipitation in the driest month of the year & 43.8 & 1.7 \\
Mean annual air temperature & 30.5 & 52.9 \\
Mean temperature in the coldest quarter of the year & 8.9 & 21.8 \\
Mean temperature in the warmest quarter of the year & 5.4 & 37.0 \\
Annual temperature amplitude & 3.1 & 8.4 \\
Average daily temperature amplitude for each month & 12.4 & 0.4 \\
Standard deviation of temperature & 2.1 & 3.8 \\
Minimal temperature in the coldest month & 1.5 & 1.1 \\
Annual precipitation sum & 1.3 & 0.4 \\
Sum of precipitation in the most humid month in the year & 0.7 & 3.4 \\
Sum of precipitation in the most warm quarter of the year & 0.5 & 2.5 \\
Isothermal & 0.3 & 0.9 \\
Sum of precipitation in the driest quarter of the year & 0.2 & 2.8 \\
Maximal temperature in the warmest month of the year & 0.2 & 0.0 \\
Mean temperature in the most humid quarter of the year & 0.1 & 0.0 \\
Sum of precipitation in the coldest quarter of the year & 0.1 & 0.2 \\
Sum of precipitation in the most humid quarter of the year & 0.0 & 0.6 \\
Mean temperature in the driest quarter of the year & 0.0 & 0.1 \\
Coefficient of variation in precipitation & 0.0 & 0.0 \\
\hline
\end{tabular}

Notes: * - percent contribution - the contribution of the factor to $P$. melanarius distribution formation; $* *$ - permutation importance - factor contribution after permutation taking into account correlation with other variables.

Species requirements to environmental temperature and precipitations are rather undemanding (Fig. 3). Species presence probability is maximal when mean temperature in the warmest quarter of the year is $+12 \ldots+23{ }^{\circ} \mathrm{C}$ (Fig. 3a) and mean temperature in the coldest quarter of the year is $10 \ldots+5{ }^{\circ} \mathrm{C}$ (Fig. 3b); mean annual temperature is wide $+5 \ldots+12{ }^{\circ} \mathrm{C}$ (Fig. 3c). The latter corresponds to the moderate (with no severe winters) climatic belt where the largest part of the range of $P$. melanarius is situated. Precipitations in the driest month of the year turned out to be less important when permutating. Herewith sum of precipitations in the driest month of the year should be 25-100 $\mathrm{mm}$ for the comfortable existence of P. melanarius (Fig. 3d).

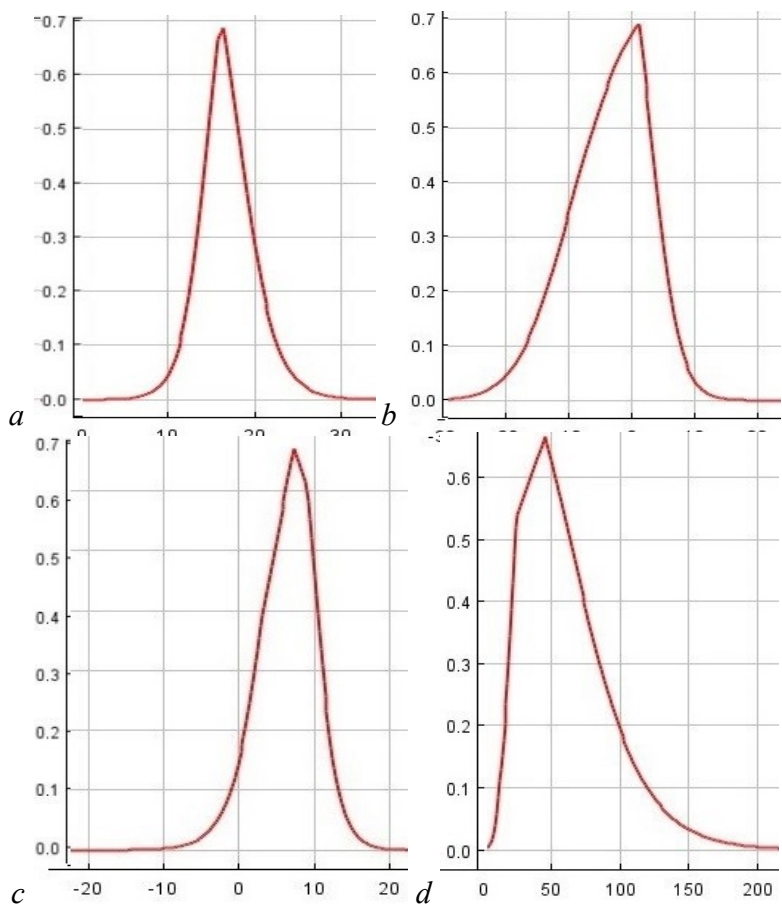

Fig. 3. Model of $P$. melanarius preferences to environmental bioclimatic factors: $a$-Bio 10 (abscissa - mean temperature in the most warm quarter of the year $\left({ }^{\circ} \mathrm{C}\right)$; ordinate - species habitat comfort index); $b$-Bio 11 (abscissa-mean temperature in the most cold quarter of the year $\left({ }^{\circ} \mathrm{C}\right)$; ordinate - species habitat comfort index); $c$ - Bio 1 (abscissa - mean annual temperature $\left({ }^{\circ} \mathrm{C}\right)$; ordinate - species habitat comfort index); $d$-Bio 14 (abscissa - sum of precipitations in the most dry month of the year ( $\mathrm{mm})$; ordinate - species habitat comfort index)
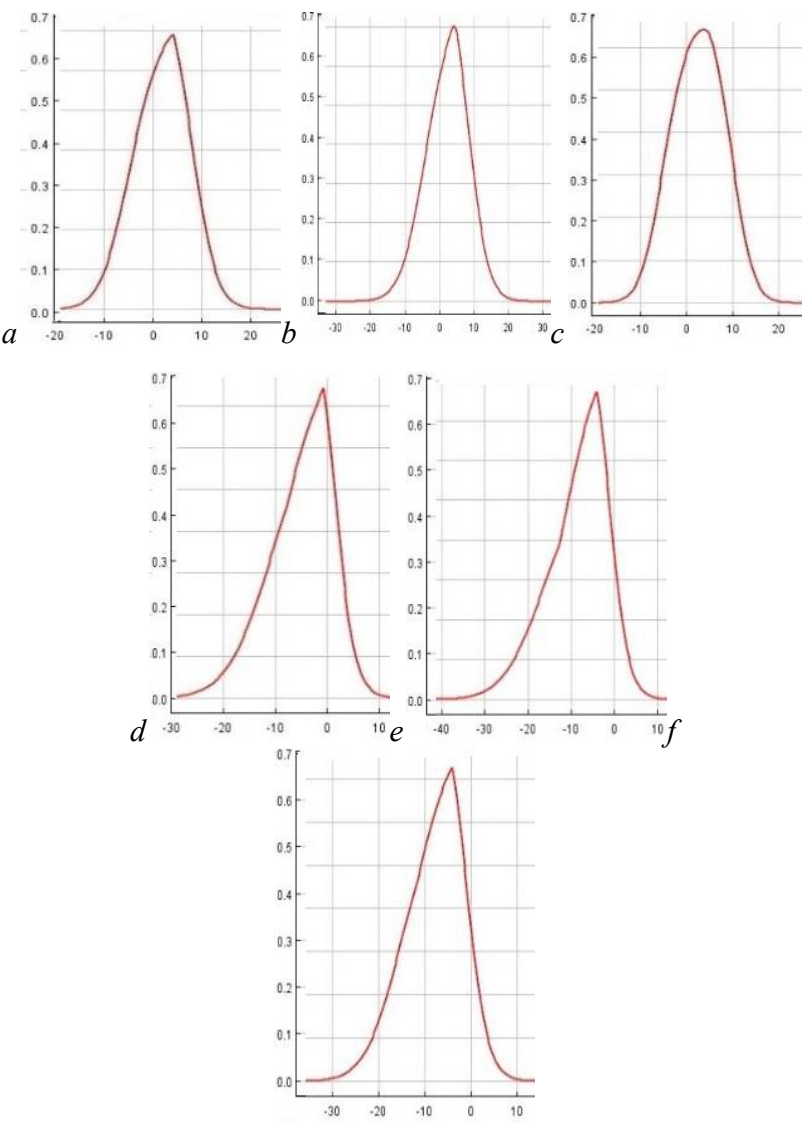

Fig. 4. Range of maximal $\left(t_{\max }\right)$ and minimal $\left(t_{\min }\right)$ temperatures in the most cold quarter of the year: $a-t_{\max }$ December, $b-t_{\max }$ January, $c-\mathrm{t}_{\max }$ February, $d-\mathrm{t}_{\min }$ December, $e-\mathrm{t}_{\min }$ January, $f-\mathrm{t}_{\min }$ February 
The most comfortable maximal temperature for $P$. melanarius in the three coldest months is $+4^{\circ} \mathrm{C}$ (Fig. 4), whereas the minimal mean monthly temperature is $-5^{\circ} \mathrm{C}$. Temperature decrease and increase can negatively affect hibernating larva and imago survival. The most comfortable mean monthly temperature in the warmest quarter of the year (Fig. 5) is $+20 \ldots+22^{\circ} \mathrm{C}$, wherein the minimal mean monthly temperature in June is $+10^{\circ} \mathrm{C}$, and in July and August is $+15^{\circ} \mathrm{C}$.

The analysis of factors' contribution to the 2050 forecast by all the scenarios showed the highest significance of mean annual temperature with the absolute maximum in RCP 8.5. Mean temperatures in the warmest and coldest quarters were significant too. Annual temperature amplitude became significant. By 2070 together with annual mean temperature, mean temperature of the coldest quarter of the year and annual temperature became the most significant. Thus, contribution of different bioclimatic variables into the spatial distribution of $P$. melanarius will change in future. But annual mean temperature and mean temperature of the coldest quarter of the year will remain the leading ones.

The Jackknife method showed the most long dark blue columns in the diagram for annual mean temperature, mean temperatures in the warmest and coldest quarters of the year. The small blue column relates to annual mean temperature. That meant that that variable exclusion leads to the serious downgrade of the model. The smaller that column, the more unique information the variable includes (Fig. 6).
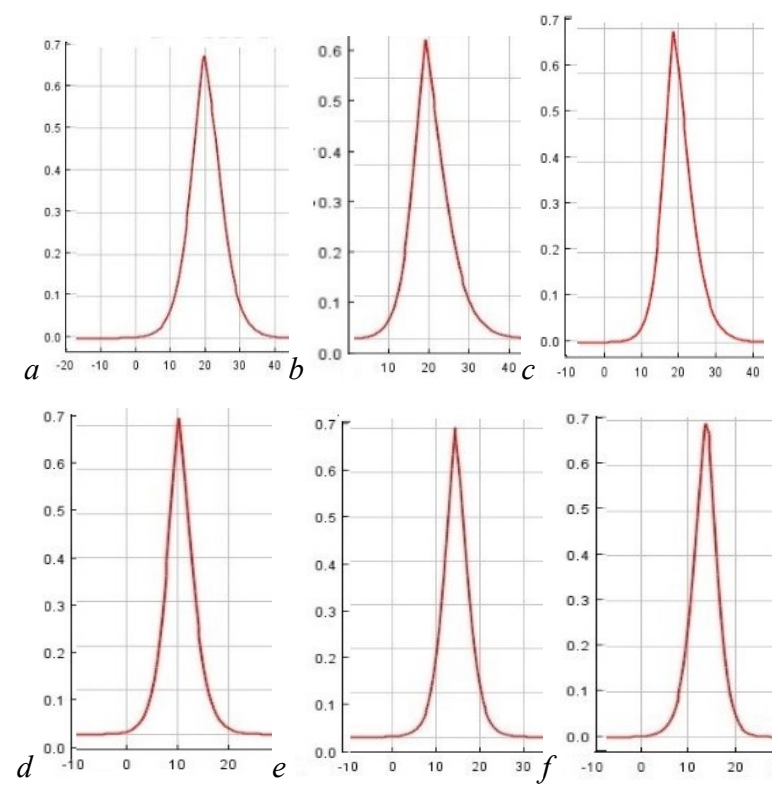

Fig. 5. Range of maximal $\left(t_{\text {max }}\right)$ and minimal $\left(t_{\text {min }}\right)$ temperatures in the most warm quarter of the year: $a-\mathrm{t}_{\max }$ June, $b-\mathrm{t}_{\max }$ July, $c-\mathrm{t}_{\max }$ August, $d-\mathrm{t}_{\min }$ June, $e-\mathrm{t}_{\min }$ July, $f-\mathrm{t}_{\min }$ August

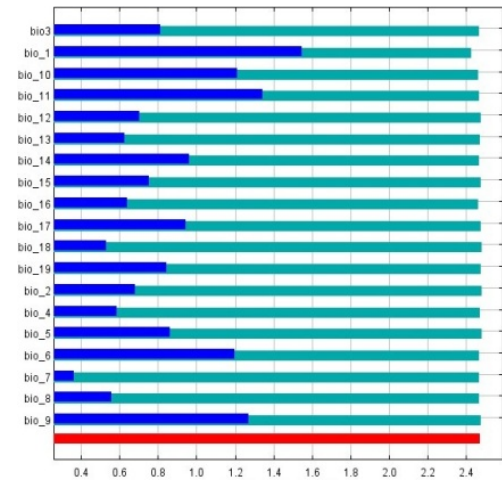

Fig. 6. Jackknife - test of training data for the present bioclimatic area in P. melanarius

We modeled 9 bioclimatic areas including bioclimatic area and the forecast areas to 2050 and 2070 by four climatic scenarios. Four territories with differing species presence likeliness were in every model: 0.8-1.0 the most probable presence likeliness; $0.6-0.8$ - high presence likeliness;
0.5-0.6 - middle presence likeliness; $0.3-0.5$ - low presence likeliness; all, that below 0.3 - the likeliness of presence are equal to zero. The value 0.3 is the threshold value of 10 percentiles.

The model of contemporary area in P. melanarius includes the zone of the most probable species presence: the southern part of Sweden, Netherland, northern and central parts of Germany, south-east coast of the Baltic Sea. France, southern and eastern parts of Germany, Poland, Czechia and Slovakia are the territories with high probability of species presence (Fig. 7). East-European and West-Siberian plains are the zones with the middle probability of species presence. The western line of the bioclimatic area passes near the western border of Tyumen oblast. The extent of the bioclimatic area with the high probability of species presence is $3,499,629 \mathrm{~km}^{2}$, with the middle values $-5,541,500 \mathrm{~km}^{2}$ and with the low ones $-7,398,277 \mathrm{~km}^{2}$

According to RCP 2.6 scenario the eastern border of area shifts towards the centre of Tyumen oblast (Fig. 8). Wherein the territories with high presence probability do not significantly change, but on the territory of the East-European plain predicted changes lead to decline of the territories bioclimatic suitability. The extent of the most probable presence contractsand becomes $3,053,767 \mathrm{~km}^{2}$. The area with the middle probability of species presence contracts too $\left(3,683,032 \mathrm{~km}^{2}\right)$, whereas the area with low presence probability increases to $8,083,575 \mathrm{~km}^{2}$.

According to the scenario RCP 2.6 model for 2070 the total area of the bioclimatic range does not change but the ratio of territories with differing suitability changes significantly (Fig. 9). So the area of the territories with high suitability increases, relatively, with low suitability - decreases (Table 2). The latter is explained by the climatic scenario 2.6, which predicts temperature drop to 2070 because of greenhouse gas emissions' reduction. It is apparent that the bioclimatic area in 2070 is similar to the contemporary one, i. e. its recovery is predicted.

Reduction of the territories with the medium suitability to 2050 is observed in the model according to 4.5 scenario. This points to changes in bioclimatic parameters and deterioration of habituation conditions on the territory of the East-European and West-Siberian Plains. The contribution of annual temperature increases. The latter probably is connected with the strengthening in the temperature regime seasonal contrast. Territories with the most favourable conditions decrease if compared with contemporary area. Part of the territories becomes less suitable for inhabitation by the studued species (Fig. 11).

To 2070 according to 4.5 scenario suitable for habitation the range widens if compared with 2050 and the contemporary range (Fig. 12,13). Annual temperature amplitude and the mean temperature of the coldest quarter become the most significant.

Table 2

Bioclimatic area size $\left(\mathrm{km}^{2}\right)$ in P. melanarius according to RCP 2.6, RCP 4.5, RCP 6.0 and RCP 8.5 scenarios

\begin{tabular}{cccccc}
\hline \multirow{2}{*}{ Period } & \multicolumn{5}{c}{ Bioclimatic habitats suitability index } \\
\cline { 2 - 6 } & $0.80-1.00$ & $0.60-0.79$ & $0.50-0.59$ & $0.30-0.49$ & $<0.30$ \\
\hline Present time & $1,768,598$ & $1,731,030$ & $5,541,005$ & $7,398,299$ & $993,811,839$ \\
\hline RCP2.6 2050 & $1,526,419$ & $1,527,347$ & $3,683,032$ & $8,083,575$ & $995,497,976$ \\
RCP2.62070 & $1,839,113$ & $1,802,263$ & $5,853,590$ & $6,545,682$ & $994,236,900$ \\
\hline RCP4.5 2050 & $1,431,803$ & $1,534,836$ & $3,536,828$ & $8,216,661$ & $995,539,616$ \\
RCP4.5 2070 & $1,784,003$ & $1,761,263$ & $5,297,020$ & $7,378,943$ & $994,107,103$ \\
\hline RCP6.0 2050 & $1,444,132$ & $1,691,726$ & $5,077,403$ & $5,763,010$ & $996,396,229$ \\
RCP6.0 2070 & $1,711,074$ & $1,722,191$ & $5,141,559$ & $6,514,348$ & $995,223,530$ \\
\hline RCP8.5 2050 & $1,847,393$ & $2,816,188$ & $5,261,753$ & $6,719,538$ & $993,595,350$ \\
RCP8.5 2070 & $1,568,172$ & $2,203,389$ & $4,844,132$ & $6,150,983$ & $995,616,614$ \\
\hline
\end{tabular}

Favourable territories with indexes $0.5-0.6$ enlarge to 2050 according to scenario RCP 6.0 prognostic model (Fig. 14). The area with the most high indexes covers $3,135,858 \mathrm{~km}^{2}$. It is higher than in the previous model. The area with the middle indexes increases significantly and covers $5,077,403 \mathrm{~km}^{2}$. The mainly contribution is from three factors: mean annual temperature, the mean temperature of the coldest quarter and annual temperature amplitude. The range extends in a north-east direction, the southern borders become less homogeneous. Thus, according to all three scenarios the same tendency is observed: to 2050 the extent of the most suitable territories decreases but by 2070 it recovers (Fig. 15, 16). 


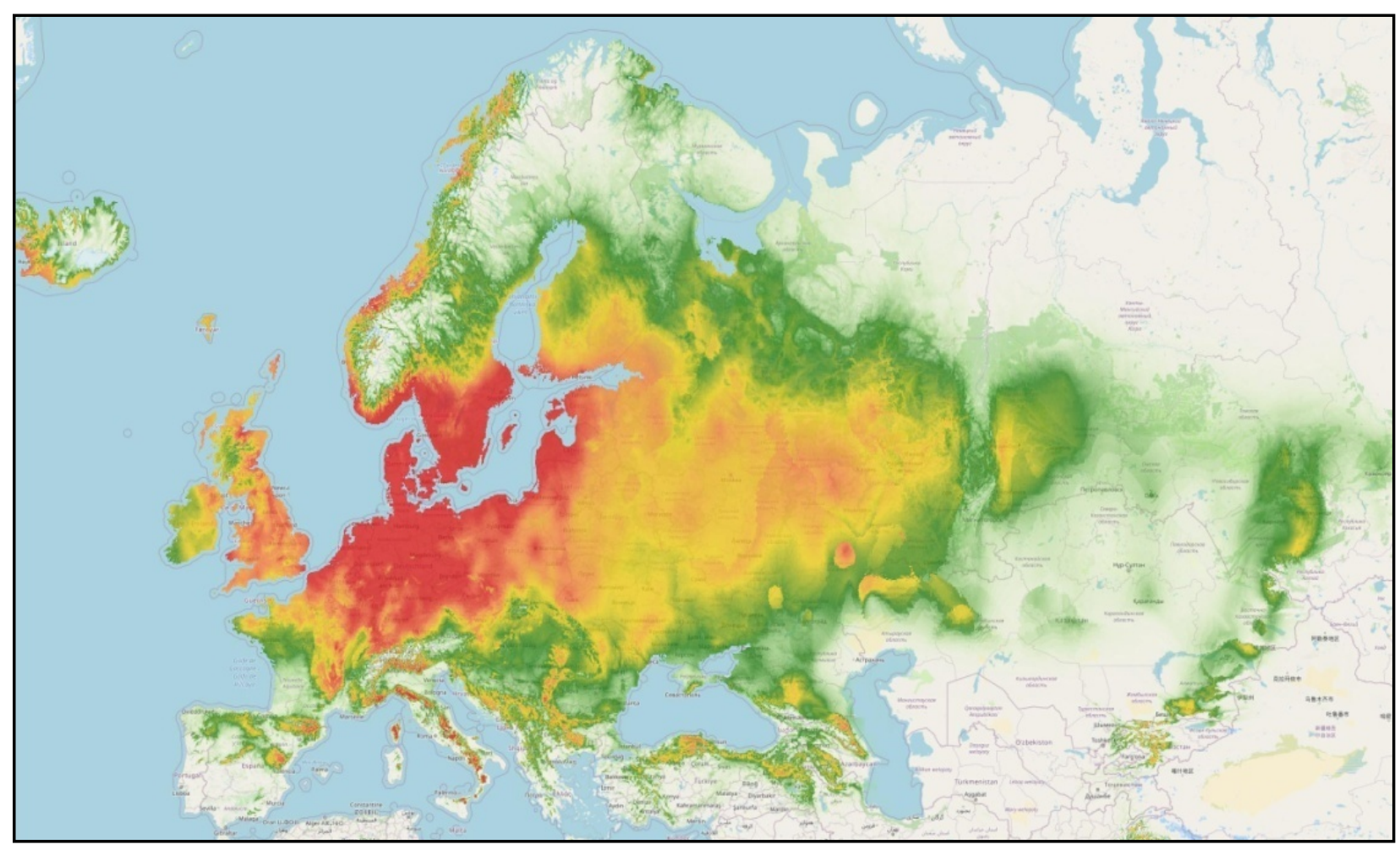

Fig. 7. Present bioclimatic area in P. melanarius:

red $-0.8-1.0$ - the most probable presence likeliness, orange $-0.6-0.8$ - high presence likeliness, yellow $-0.5-0.6$ - middle presence likeliness, green $-0.3-0.5$ - low presence likeliness

Only in the most "severe" RCP 8.5 scenario is the area of suitable territories gradually reduced, the bioclimatic area becomes more disjunct. The eastern part of the range transforms significantly affecting EastEuropean and West-Siberian plains (Fig. 17, 18).

Our models show that the total range does not change significantly. Some factors become more important and favourability of territories worsens. In the more "soft" scenarios the territory with favourable conditions decreases, the range transforms towards decline insuitability.

In this relation, the territories with high suitability level are the most stable. There no significant changes there. Territories with the middle suitability level are less stable. Their properties worsen when bioclimatic parameters change. Central parts of the Eurasian continent significantly transform. Annual temperature amplitude contribution strengthens. Probably the continentality index increases against the background of climate changes. That effect is not observed in the coastal territories. Probably seasonal temperature differences appear there not so drastically.

We can suggest that dynamics of environment parameters in the same habitats in different years can affect species number no less strongly. Long-term population abundance cycles are complex and vary highly. Changes in number, population density and niche occupancy extend to several years and are accompanied by the population phases dynamics series. Probably these factors affect the range expansion or reduction too.

\section{Discussion}

Observed climate changes at present include significant increase of temperature in the cold seasons of the year, the increase of evaporation when precipitation values do not change and even decrease, increased frequency of droughts, changes in annual river flows and their seasonal redistribution, changes in ice cover in the Arctic Ocean and north river mouths. These changes should affect species present and predicted range. In this connection investigation of climatic factors affecting species distribution becomes relevant.

High AUC indexes confirmed good results of all our models in potential distribution. The maps received characterize reliably the studied species distribution peculiarities. Mean temperature of the coldest and the warmest quarters, mean annual temperature contributed highly in the mo- dels construction. The key parameters set changed significantly when we modeled the probable area taking into account climatic trends to 2050 and 2070. Mean annual temperature effect reduces but mean temperature of the coldest quarter in an year increases. The importance of mean annual temperature rises to 2050 according to all scenarios.

The southern part of Sweden and the whole territory of the Baltic ridge are the most climatically suitable regions according to the GISmodel of the present area of the species. Comfort coefficient is near 1 .

Considering the possible changes in $P$. melanarius range in the second part of the XXI century, the tendency is observed of transition in the range northwest in the continental countries and northeast in the coastal ones. Thus, according to "severe" scenario RCP 8.5 by 2070 practically all the southern territories of Europea become unsuitable for $P$. melanarius habitatation. Range shift to the north in the eastern part of the European plain is most noticeable. The range widens in the south of the WestSiberian. The expanding zone of suitable conditions in the Altay can be noted as well.

By 2070 mountain territories, situated in Europe, including the Alps, Carpathians, Urals, Caucasus become less suitable. By 2070 P. melanarius range will decrease on the Balkan peninsula. Thus, the sharp decrease in abundance in south European, Mediterranean populations should be expected (Zamotajlov \& Kryzhanovskij, 1992). Herewith change in climate conditions will not lead to a one-time change in the range of the studied species. It will determine the tendency of its step-by-step transition to an optimal bioclimatic conditions region.

Changing environment can impact food resources of the studied species. The latter can change the range borders as well (Wallin, 1988; Thomas et al., 1998, 2008; Foltan, 2004; Paill, 2004).

The decrease in $P$. melanarius (it is zoophage) abundance can affect numbers of some pests in certain regions of South Europe (Armstrong \& McKinlay, 1997; Chapman et al., 1999; Fournier \& Loreau, 2001; Brunke et al., 2009). We must take into account that such abundant predator carabid extinction in forests and agrocenoses inevitably will lead to changes in the abundance ratio of other predators (Dixon \& McKinlay, 1992; Dinter, 1998). Certainly our study was done in some degree on the local level, though the data used included the greater part of Eurasia. So we do not insist on the absolute validity of our conclusions. 


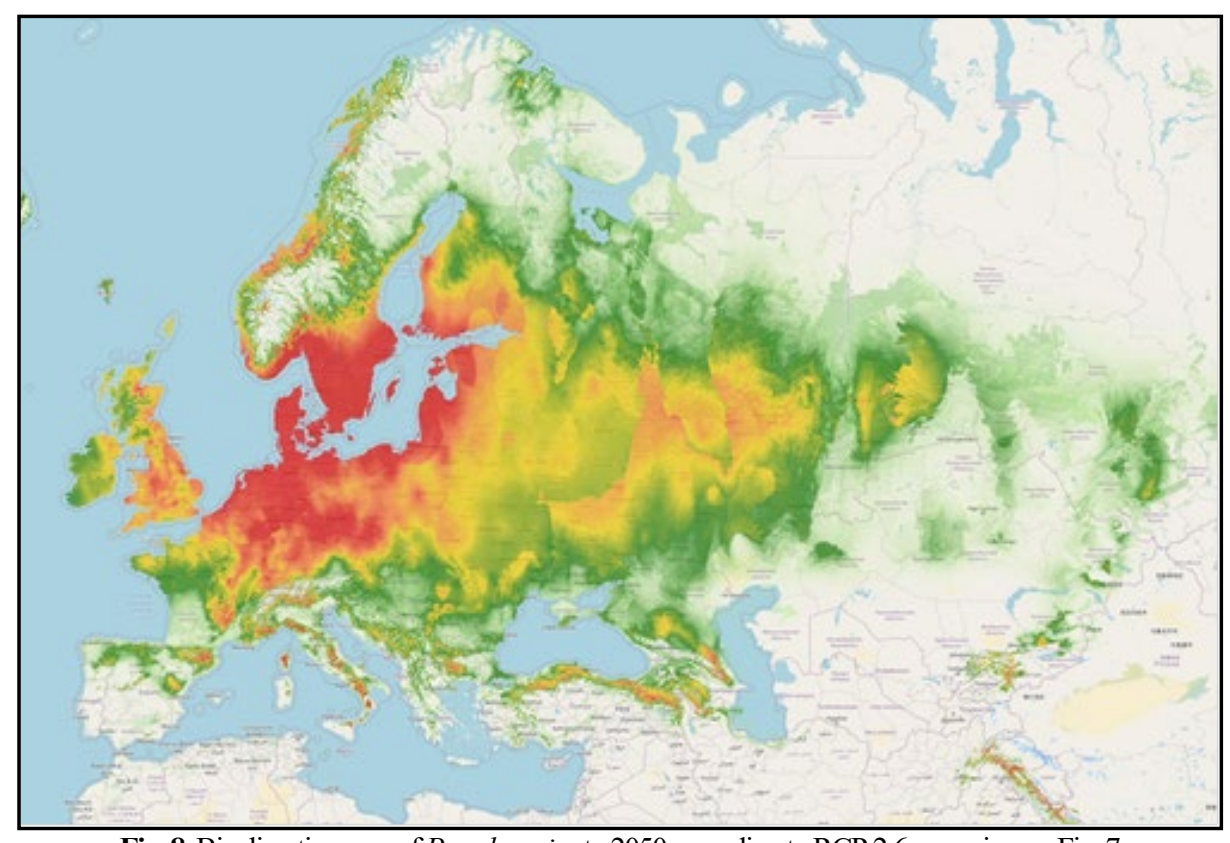

Fig. 8. Bioclimatic range of P. melanarius to 2050 according to RCP 2.6 scenario: see Fig. 7

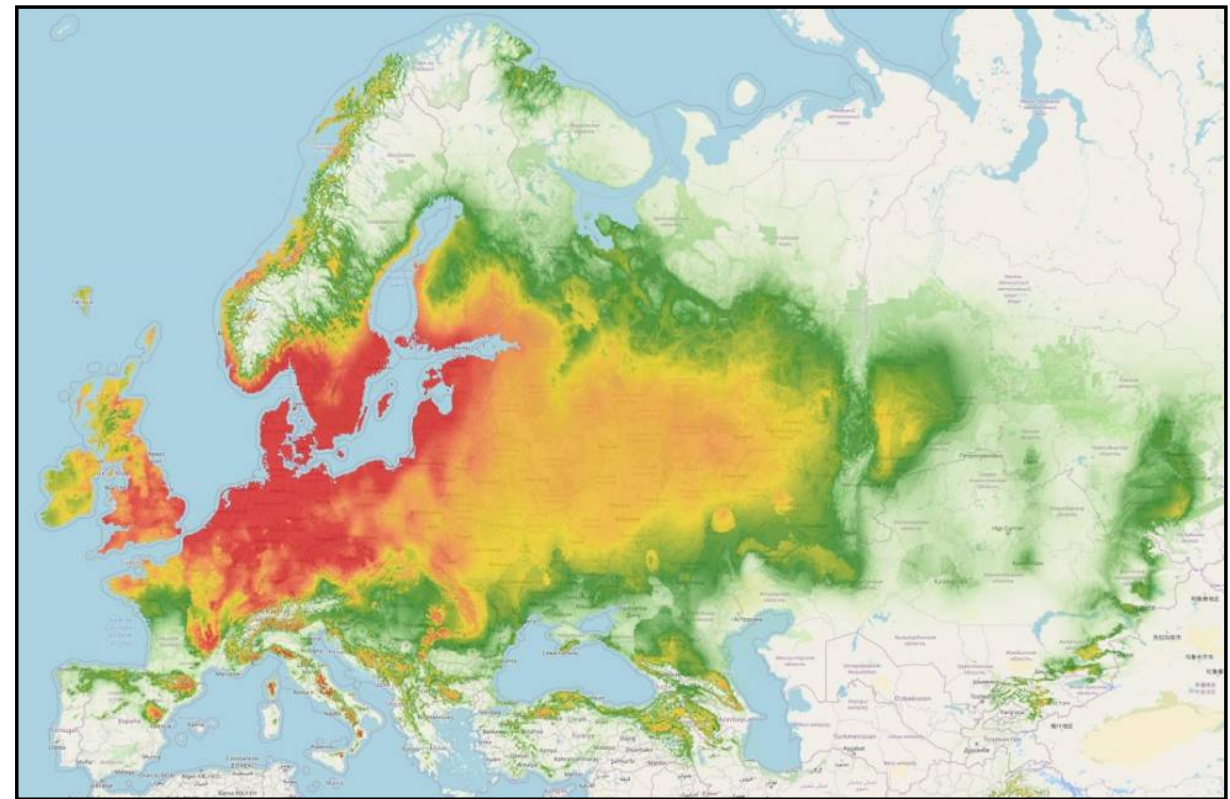

Fig. 9. Bioclimatic range of $P$. melanarius to 2070 according to RCP 2.6 scenario: see Fig. 7

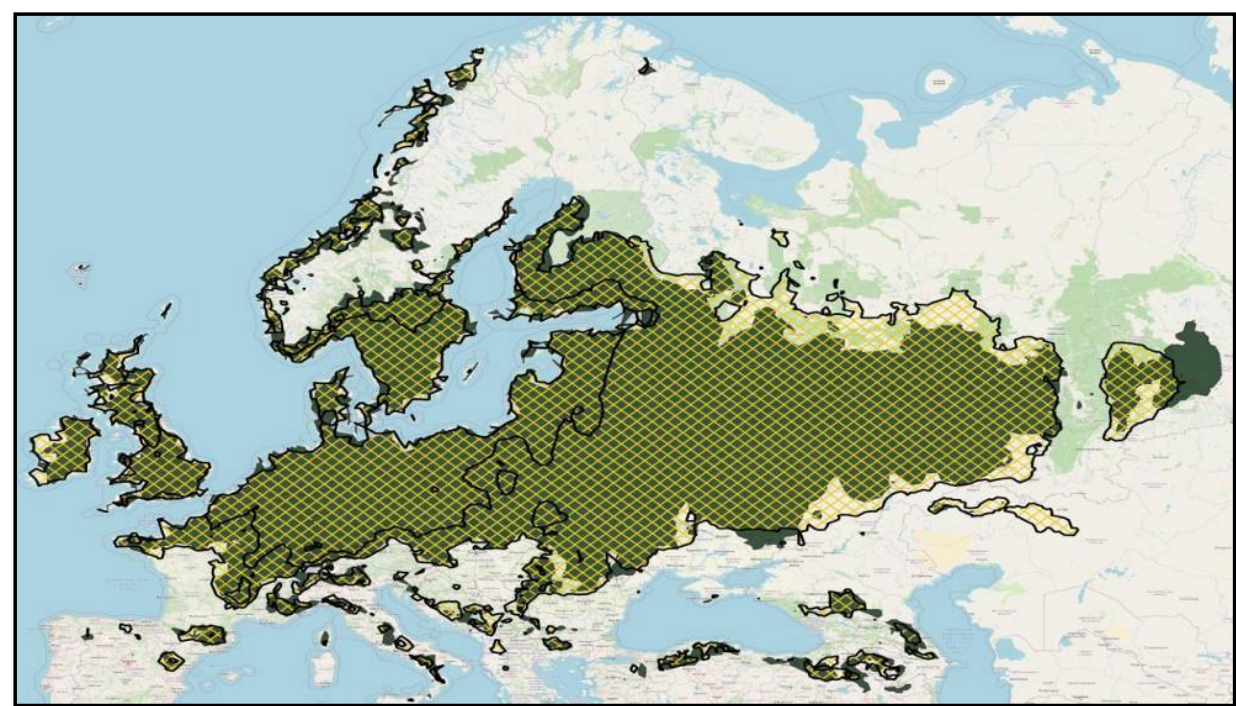

Fig. 10. Comparison of bioclimatic ranges according to RCP 2.6 scenario: $[-2050 ;-1 \square-2070$ 


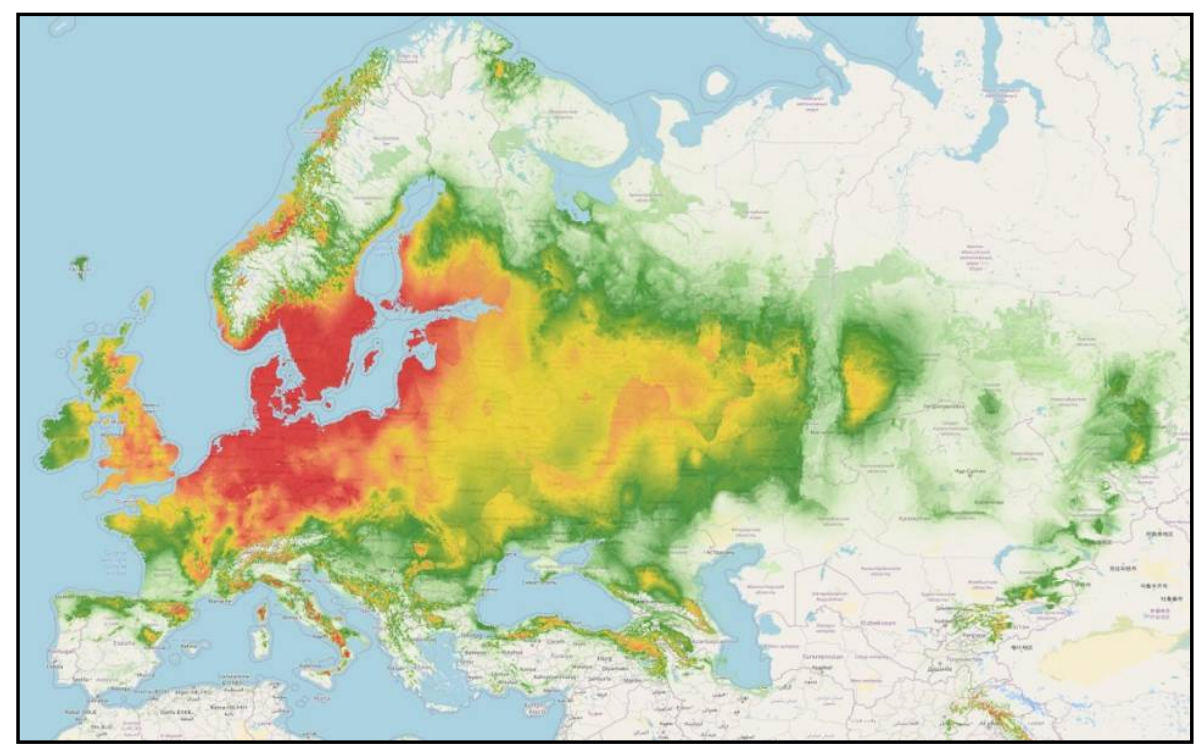

Fig. 11. Bioclimatic range of $P$. melanarius to 2050 according to RCP 4.5 scenario: see Fig. 7

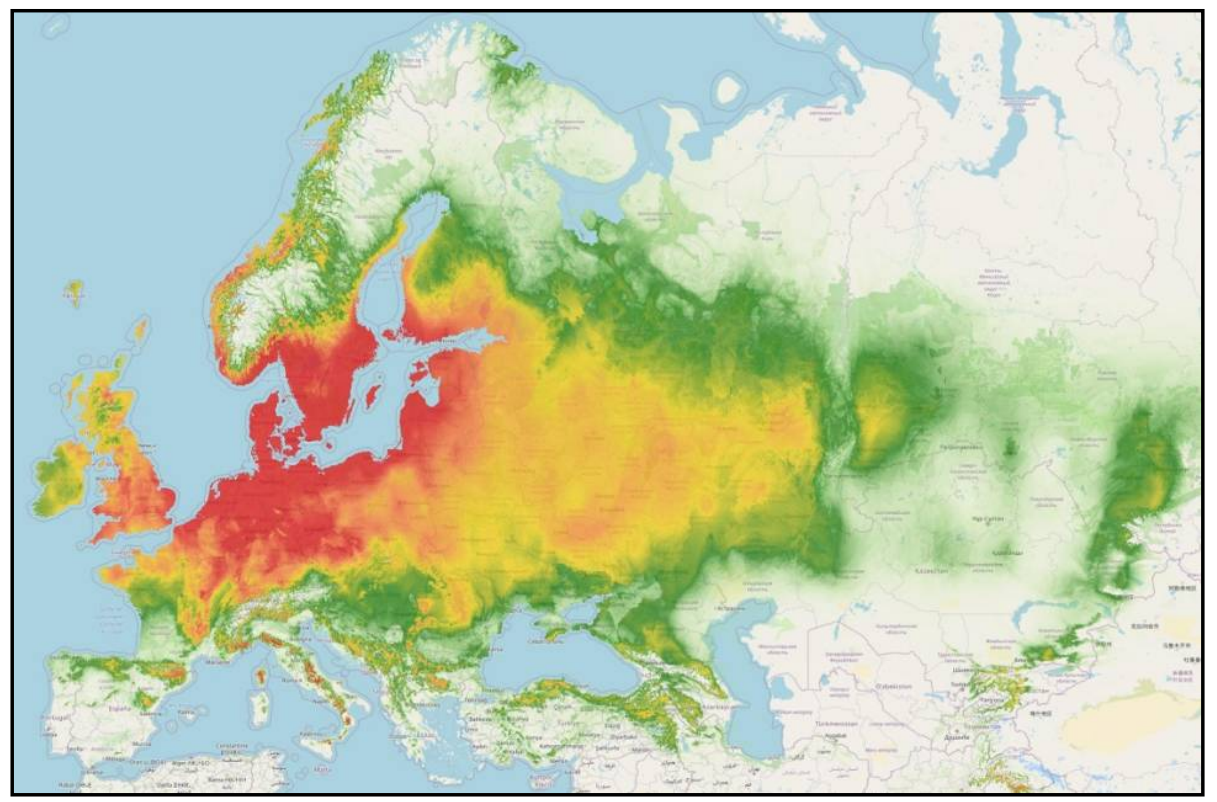

Fig. 12. Bioclimatic range of $P$. melanarius to 2070 according to RCP 4.5 scenario: see Fig. 7

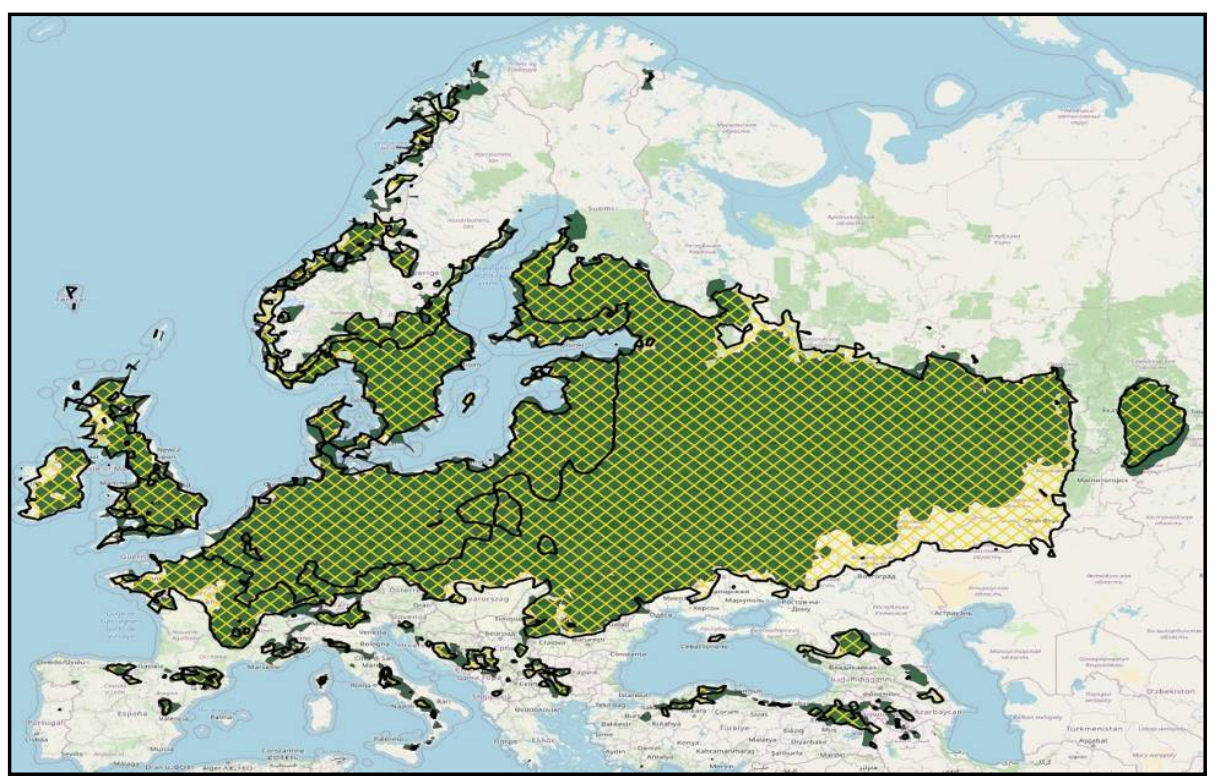

Fig. 13. Comparison of bioclimatic ranges according to RCP 4.5 scenario: $[-2050 ;-[-2070$ 


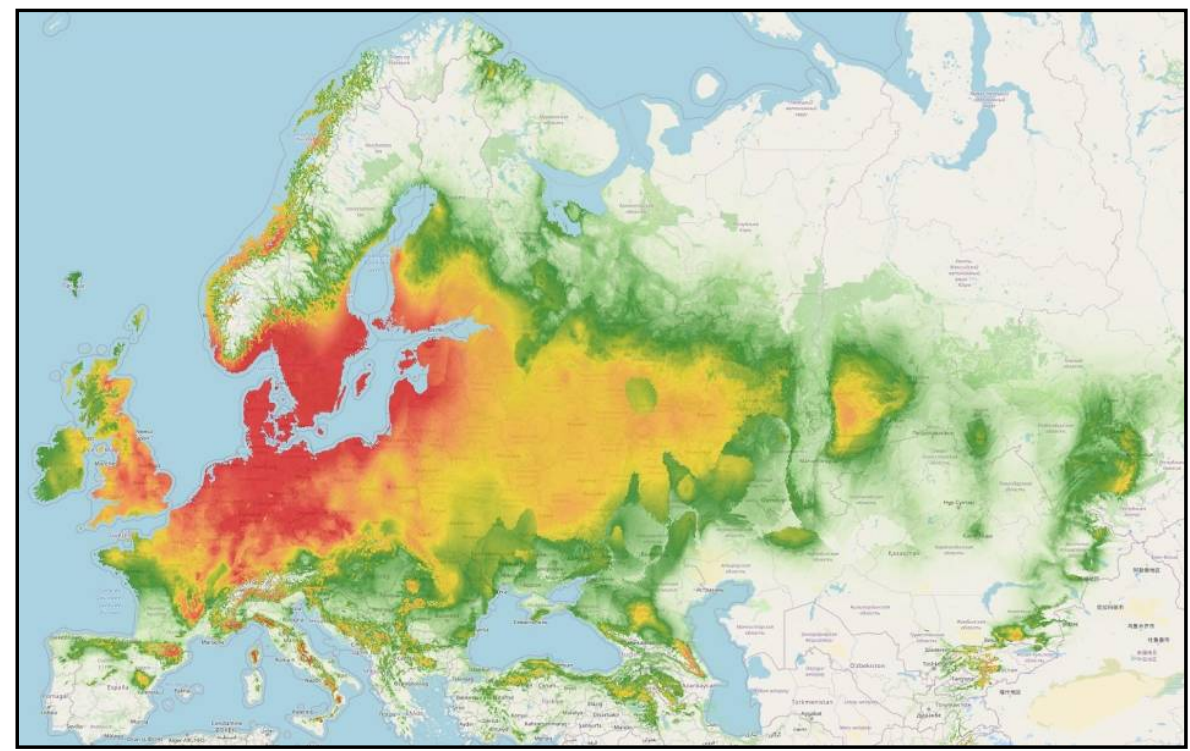

Fig. 14. Bioclimatic range of P. melanarius to 2050 according to RCP 6.0 scenario: see Fig. 7

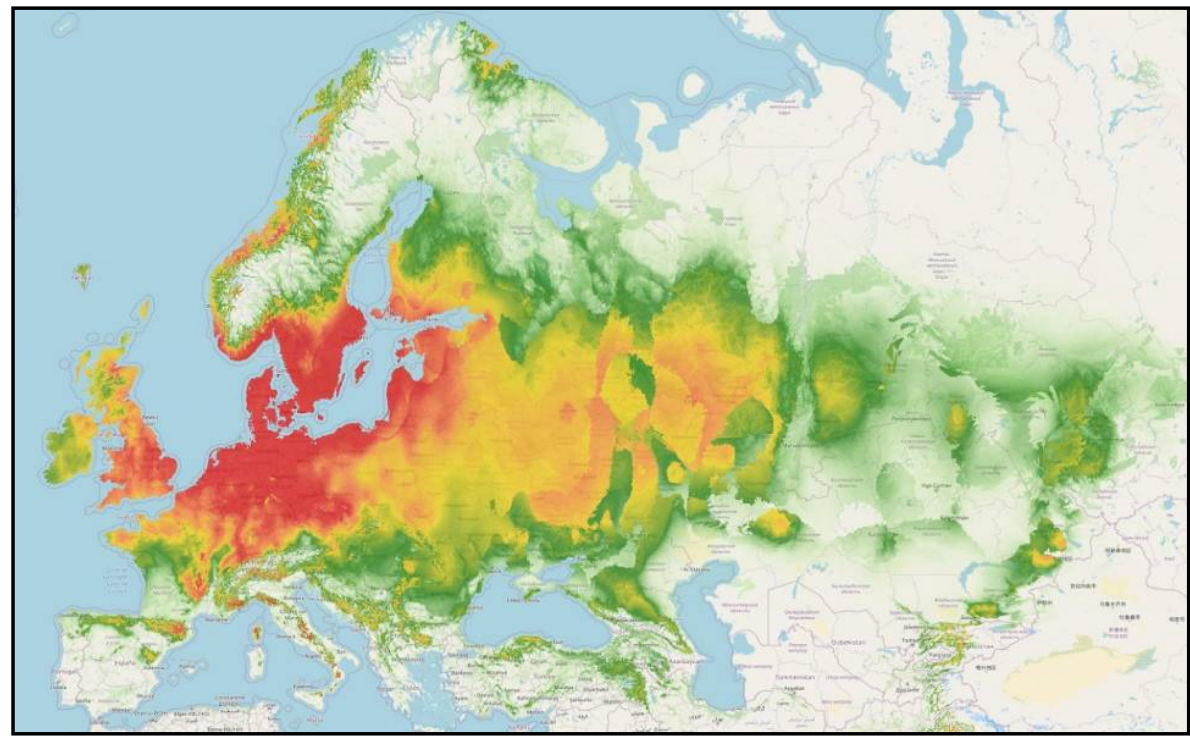

Fig. 15. Bioclimatic range of P. melanarius to 2070 according to RCP 6.0 scenario: see Fig. 7

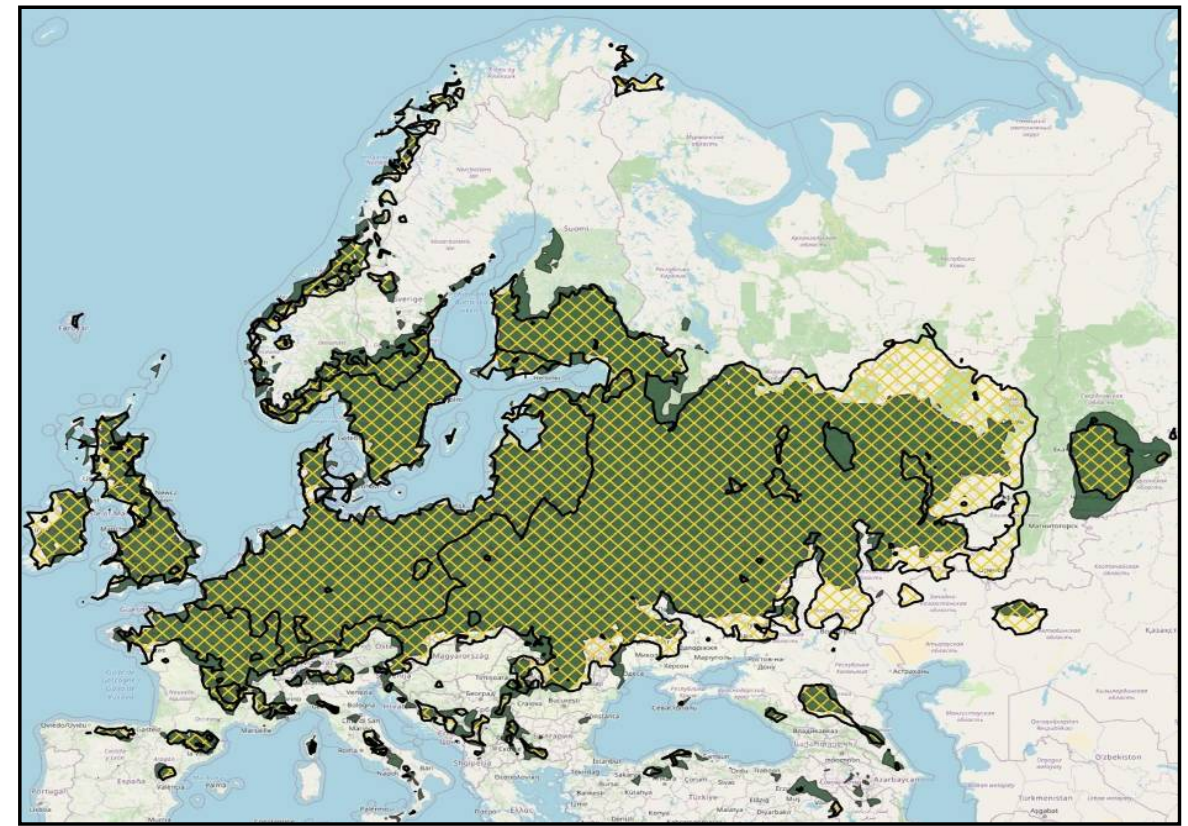

Fig. 16. Comparison of bioclimatic ranges according to RCP 6.0 scenario: $\square-2050 ;-1 \square-2070$ 


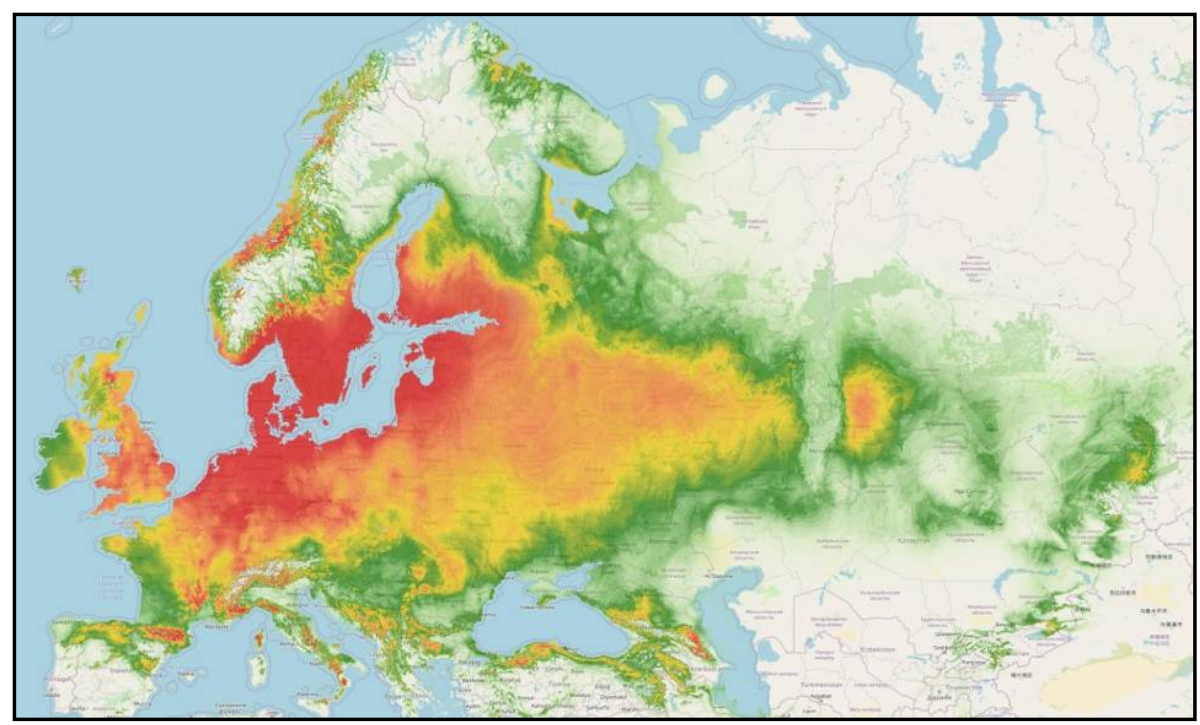

Fig. 17. Bioclimatic range of P. melanarius to 2050 according to RCP 8.5 scenario: see Fig. 7

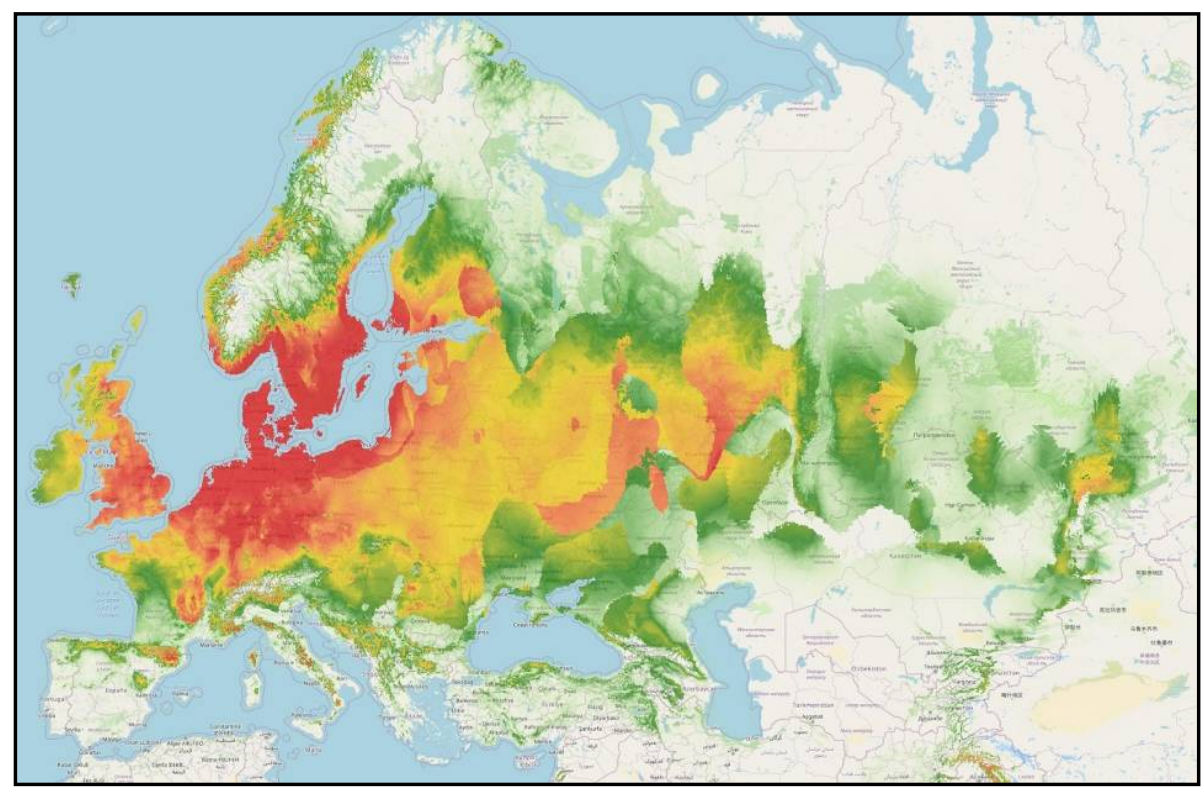

Fig. 18. Bioclimatic range of $P$. melanarius to 2070 according to RCP 8.5 scenario: see Fig. 7

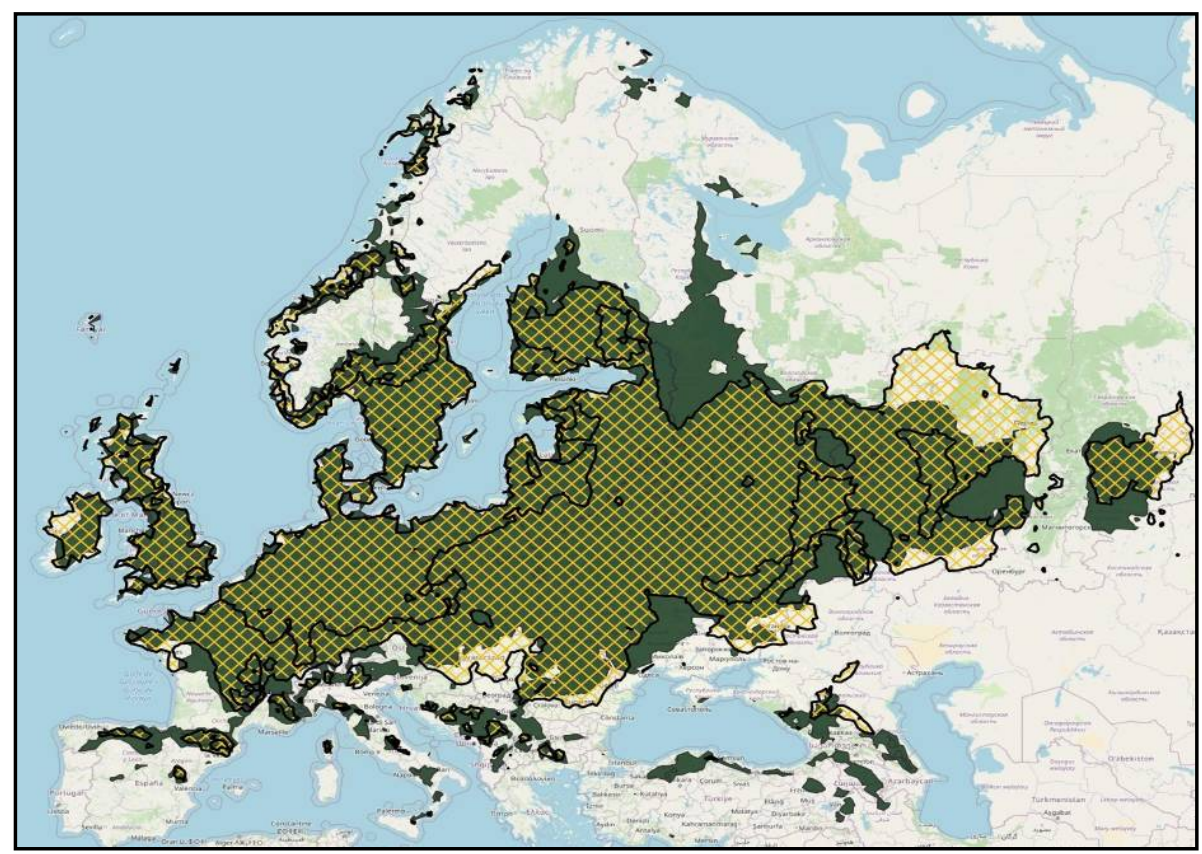

Fig. 19. Comparison of bioclimatic ranges according to RCP 8.5 scenario: $\square-2050 ;-2070$ 
Bioclimate parameters changes affect beetles' life-cycles. Shifts in temperature values in the coldest and the warmest quarters of the year can prolong the duration of larvae development (Plotkin, 1979; Firle et al., 1998; Matalin, 2006). Activity periods and, related to them, duration of the reproduction period are the most variable parameters in insects' lifecycles. The latter vary both in different climatic zones or different altitudes and in the same climatic zone as well. They are directly dependent on climate factors. According to laboratory experiments it takes no less than three weeks for the normal gonad maturation in P. melanarius with temperature $+20{ }^{\circ} \mathrm{C}$ (Trushitsyna \& Matalin, 2016). Our results confirm this data: the optimum of the maximal temperatures in the warmest quarter is $+15 \ldots+20^{\circ} \mathrm{C}$ and the optimum of the maximal temperatures in the coldest quarter is $-5 \ldots+3^{\circ} \mathrm{C}$.

\section{Conclusion}

According to analysis of the distribution of $P$. melanarius by means of the maximal entropy, the main factors affecting its distribution are the mean temperature in the warmest and coldest quarters of the year, the mean annual temperature and precipitations in the driest month. Bioclimatic changes according to RCP 8.5 scenario will lead to the quadruple reduction of the present area, to significant reduction of the most favourable territories with high abundance, to the shift of climatic optimum territories to the northwest in the continental part and to the northeast - in the coastal part of the species' range. A considerable proportion of mountain territories become unsuitable for habitation. The forecast maps for the species' distribution for the modeled scenario show a species-specific response to possible climate changes. Significant reduction in the current range is expected with the shifts to the north, a reduction in the number of sites inhabited by $P$. melanarius and reduction in its abundance across the whole of southern Europe.

\section{References}

Armstrong, G., \& McKinlay, R. G. (1997). Vegetation management in organic cabbages and pitfall catches of carabid beetles. Agriculture, Ecosystems and Environment, 64(3), 267-276.

Avtaeva, T. A., Sukhodolskaya, R. A., Skripchinsky, A. V., \& Brygadyrenko, V. V. (2019). Range of Pterostichus oblongopunctatus (Coleoptera, Carabidae) in conditions of global climate change. Biosystems Diversity, 27(1), 76-84.

Banks, J. E. (1999). Differential response of two agroecosystem predators, Pterostichus melanarius (Coleoptera: Carabidae) and Coccinella septempunctata (Coleoptera: Coccinellidae), to habitat-composition and fragmentation-scale manipulations. The Canadian Entomologist, 131(5), 645-657.

Bousquet, Y. (2003). Tribe Pterostichini. In: Löbl, J., \& Smetana, A. (Eds.). Catalogue of Palearctic Coleoptera. Vol. 1. Archostemata - Myxophaga - Adephaga. Apollo Books, Stenstrup. Pp. 462-521.

Brunke, A. J., Bahlai, C. A., Sears, M. K., \& Hallett, R. H. (2009). Generalist predators (Coleoptera: Carabidae, Staphylinidae) associated with millipede populations in sweet potato and carrot fields and implications for millipede management. Environmental Entomology, 38(4), 1106-1116.

Brygadyrenko, V. V. (2015). Parameters of ecological niches of Badister, Licinus and Panagaeus (Coleoptera, Carabidae) species measured against eight ecological factors. Baltic Joumal of Coleopterology, 15(2), 137-154.

Brygadyrenko, V. V. (2016). Evaluation of ecological niches of abundant species of Poecilus and Pterostichus (Coleoptera: Carabidae) in forests of the steppe zone of Ukraine. Entomologica Fennica, 27(2), 81-100.

Brygadyrenko, V. V., \& Korolev, O. V. (2006). Peculiarities of trophic spectrum of Pterostichus melanarius (Coleoptera: Carabidae) in laboratory conditions. Visnyk Bilocerkivskogo Derzhavnogo Agramogo Universitetu, 43, 67-71.

Brygadyrenko, V. V., \& Korolev, O. V. (2015). Morphological polymorphism in an urban population of Pterostichus melanarius (Illiger, 1798) (Coleoptera, Carabidae). Graellsia, 71(1), e025.

Carmona, D. M., \& Landis, D. A. (1999). Influence of refuge habitats and cover crops on seasonal activity-density of ground beetles (Coleoptera: Carabidae) in field crops. Environmental Entomology, 28(6), 1145-1153.

Chapman, P. A., Armstrong, G., \& McKinlay, R. G. (1999). Daily movements of Pterostichus melanarius between areas of contrasting vegetation density within crops. Entomologia Experimentalis et Applicata, 91(3), 479- 482.

Cottrell-Callbeck, S., MacDonald, M., \& Evenden, M. (2019). Wing polymorphisms of Pterostichus melanarius (Coleoptera: Carabidae) (Illiger, 1978) in Alberta pulse crops. Alberta Academic Review, 2(2), 23-24.

Dinter, A. (1998). Intraguild predation between erigonid spiders, lacewing larvae and carabids. Joumal of Applied Entomology, 122, 163-167.
Dixon, P. L., \& McKinlay, R. G. (1992). Pitfall trap catches of and aphid predation by Pterostichus melanarius and Pterostichus madidus in insecticide treated and untreated potatoes. Entomologia Experimentalis et Applicata, 64(1), 63-72.

Elek, Z., Lövei, G., \& Bátki, M. (2014). No increase in fluctuating asymmetry in ground beetles (Carabidae) as urbanisation progresses. Community Ecology, 15(2), 131-138.

Firle, S., Bommarco, R., Ekbom, B., \& Natiello, M. (1998). The influence of movement and resting behavior on the range of three carabid beetles. Ecology, 79(6), 2113-2122.

Foltan, P. (2004). Influence of slug defence mechanisms on the prey preferences of the carabid predator Pterostichus melanarius (Coleoptera: Carabidae). European Joumal of Entomology, 101(3), 359-364.

Fournier, E., \& Loreau, M. (2001). Activity and satiation state in Pterostichus melanarius: An experiment in different agricultural habitats. Ecological Entomology, 26(3), 235-244.

Freude, H., Harde, K. W., \& Lohse, G. A. (2004). Die Käfer Mitteleuropas. Band 2. Adephaga. 1. Carabidae (Laufkäfer). Elsevier, Spektrum Akademischer Verlag, Heidelberg.

Hawthome, A., Hassall, M., \& Sotherton, N. (1998). Effects of cereal headland treatments on the abundance and movements of three species of carabid beetles. Applied Soil Ecology, 9, 417-422.

Kielty, J. P., Allen-Williams, L. J., \& Underwood, N. (1999). Prey preferences of six species of Carabidae (Coleoptera) and one Lycosidae (Araneae) commonly found in UK arable crop fields. Journal of Applied Entomology, 123(4), 193-200.

Komlyk, V. O., \& Brygadyrenko, V. V. (2019). Morphological variability of Bembidion minimum (Coleoptera, Carabidae) populations under the influence of natural and anthropogenic factors. Biosystems Diversity, 27(3), 250-269.

Korolev, O. V., \& Brygadyrenko, V. V. (2012a). Comparative analysis of Pterostichus melanarius (Coleoptera, Carabidae) trophic preferences in different condition of laboratory keeping. Optimization and Protection of Ecosystems, 6, 178-190.

Korolev, O. V., \& Brygadyrenko, V. V. (2012b). Trophic relations of Pterostichus melanarius (Coleoptera, Carabidae) with dominant species of invertebrates in forest ecosystems of steppe Dnieper region. Visnyk of Dnipropetrovsk University, Biology, Ecology, 20(1), 48-54.

Korolev, O. V., \& Brygadyrenko, V. V. (2014). Influence of individual variation in the trophic spectra of Pterostichus melanarius (Coleoptera, Carabidae) on the adaptation possibilities of its population. Folia Oecologica, 41(1), $34-43$.

Kryzhanovskij, O. L., Belousov, I. A., Kabak, I. I., Kataev, B. M., Makarov, K. V., \& Shilenkov, V. G. (1995). A checklist of the ground-beetles of Russia and adjacent lands (Insecta, Coleoptera, Carabidae). Pensoft Publishers, Sofia, Bulgaria.

Lindqvist, L., \& Block, M. (2001). Metal pollution and fat accumulation in the carabid beetle Pterostichus melanarius (Coleoptera, Carabidae). Bulletin of Environmental Contamination and Toxicology, 66(2), 184-188.

Magura, T., Tóthmérész, B., \& Molnár, T. (2008). A species-level comparison of occurrence pattems in carabids along an urbanisation gradient. Landscape and Urban Planning, 86(2), 134-140.

Matalin, A. V. (2006). Geographic variability of the life cycle in Pterostichus melanarius (Coleoptera, Carabidae). Entomological Review, 86(4), 409-422.

Niemelä, J., \& Spence, J. R. (1994). Community impacts of an exotic carabid: Pterostichus melanarius in western Canadian forests. In: Desender, K., Dufrene, M., Loreau, M., Luff, M. L., \& Maelfait, J.-P. (Eds.). Carabid beetles: Ecology and evolution. Springer Nature. Pp. 331-335.

Niemela, J., Spence, J. R., \& Carcamo, H. (1997). Establishment and interactions of carabid populations: An experiment with native and introduced species. Ecography, 20(6), 643-652.

Paill, W. (2004). Slug feeding in the carabid beetle Pterostichus melanarius: Seasonality and dependence on prey size. Journal of Molluscan Studies, 70(2), 203-205.

Plotkin, H. C. (1979). Learning in a carabid beetle (Pterostichus melanarius). Animal Behaviour, 27, 567-575.

Putchkov, A. (2011). Ground beetles of the Ukraine (Coleoptera, Carabidae). ZooKeys, 100, 503-515.

Putchkov, A. V. (2018). Zhuky-turuny (Coleoptera, Carabidae) transformovanykh tsenoziv Ukrajiny [Ground-beetles (Coleoptera, Carabidae) of transformed cenoses of Ukraine]. I. I. Schmalhausen Institute of Zoology, Kyiv (in Ukrainian).

Putchkov, A. V., Brygadyrenko, V. V., \& Markina, T. Y. (2019). Ground beetles of the tribe Carabini (Coleoptra, Carabidae) in the main megapolises of Ukraine. Vestnik Zoologii, 53(1), 3-12

Putchkov, A. V., Brygadyrenko, V. V., \& Nikolenko, N. Y. (2020). Ecological and faunistic review of beetles (Coleoptera: Carabidae, Cicindelidae) of megapolises of Ukraine. Biosystems Diversity, 28(2), 189-199.

Sharova, I. K., \& Denisova, M. I. (1997). Seasonal dynamics of carabid populations from the genus Pterostichus (Coleoptera, Carabidae). Zoologichesky Zhurnal, 76(4), $418-427$.

Sharova, I. K., Popova, A. A., \& Romankina, M. Y. (1998). Ecological differentiation of mass carabid species (Coleoptera, Carabidae) in agrocenoses. Zoologichesky Zhumal, 77(12), 1377-1382. 
Sukhodolskaya, R. (2014). Variation in body size and body shape in ground beetle Pterostichus melanarius Ill. (Coleoptera, Carabidae). Joumal of Agri-Food and Applied Sciences, 2(7), 196-205.

Sukhodolskaya, R. A. (2013). Intraspecific body size variation in ground beetles (Coleoptera, Carabidae) in urban-suburban-rural-natural gradient. Acta Biologica Universitatis Daugavpiliensis, 13(1), 121-128.

Symondson, W. O. C., Erickson, M. L., \& Liddell, J. E. (1999). Development of a monoclonal antibody for the detection and quantification of predation on slugs within the Arion hortensis agg. (Mollusca: Pulmonata). Biological Control, 16(3), 274-282.

Symondson, W. O. C., Erickson, M. L., \& Liddell, J. W. (1997). Species-specific detection of predation by coleoptera on the milacid slug Tandonia budapestensis (Mollusca: Pulmonata). Biocontrol Science and Technology, 7(3), 457-465.

Thiele, H. U. (1977). Carabid beetles in their environments. Springer-Verlag, Berlin.

Thomas, C. F. G., Green, F., \& Marshall, E. J. P. (1997). Distribution, dispersal and population size of the ground beetles, Pterostichus melanarius (Illiger) and Harpalus rufipes (De Geer) (Coleoptera, Carabidae), in field margin habitats.
In: Marshall, E. (Ed.). Biological agriculture and horticulture. European Workshop on Entomological Research in Organic Agriculture, 15, 337-352.

Thomas, C. F. G., Parkinson, L., \& Marshall, E. J. P. (1998). Isolating the components of activity-density for the carabid beetle Pterostichus melanarius in farmland. Oecologia, 116, 103-112.

Thomas, R. S., Glen, D. M., \& Symondson, W. O. C. (2008). Prey detection through olfaction by the soil-dwelling larvae of the carabid predator Pterostichus melanarius. Soil Biology and Biochemistry, 40(1), 207-216.

Trushitsyna, O. S., \& Matalin, A. V. (2016). Specific features of the life cycle of Pterostichus melanarius (Coleoptera, Carabidae) in mosaic floodplain meadows. Entomological Review, 96, 144-159.

Wallin, H. (1988). Mandible wear in the carabid beetle Pterostichus melanarius in relation to diet and burrowing behaviour. Entomologia Experimentalis et Applicata, 48(1), 43-50.

Zamotajlov, A. S., \& Kryzhanovskij, O. L. (1992). Materialy k izucheniju kavkazskikh zhuzhelitc triby Pterostichini (Coleoptera, Carabidae) [Materials for the study of Caucasian species of ground beetles of Pterostichini tribe (Coleoptera, Carabidae)]. Entomological Review, 71(2), 351-358 (in Russian). 